\title{
Impact on Awake Mapping on Overall Survival and Extent of Resection in Patients With Adult Diffuse Gliomas Within or Near Eloquent Areas: A Retrospective Propensity Score-matched Analysis of Awake Craniotomy Vs. General Anesthesia
}

\author{
Atsushi Fukui \\ Tokyo Women's Medical University: Tokyo Joshi Ika Daigaku \\ Yoshihiro Muragaki ( $\nabla$ ymuragaki@twmu.ac.jp ) \\ Tokyo Women`s Medical University https://orcid.org/0000-0001-8336-5328 \\ Taiichi Saito \\ Tokyo Women's Medical University: Tokyo Joshi Ika Daigaku \\ Masayuki Nitta \\ Tokyo Women's Medical University: Tokyo Joshi Ika Daigaku \\ Shunsuke Tsuzuki \\ Tokyo Women's Medical University: Tokyo Joshi Ika Daigaku \\ Hidetsugu Asano \\ Tokyo Women's Medical University: Tokyo Joshi Ika Daigaku \\ Takakazu Kwamata \\ Tokyo Women's Medical University: Tokyo Joshi Ika Daigaku
}

\section{Research Article}

Keywords: Awake craniotomy, glioma, overall survival, propensity score matching, extent of resection

Posted Date: April 6th, 2021

DOI: https://doi.org/10.21203/rs.3.rs-377735/v1

License: (c) (i) This work is licensed under a Creative Commons Attribution 4.0 International License. Read Full License

Version of Record: A version of this preprint was published at Acta Neurochirurgica on October 4th, 2021. See the published version at https://doi.org/10.1007/s00701-021-04999-6. 


\section{Abstract}

Introduction: Awake craniotomy (AC) with intraoperative mapping is the best approach to preserve neurological function for glioma surgery in eloquent or near eloquent areas, but whether AC improves the extent of resection (EOR) is controversial. Furthermore, there is less evidence of improved overall survival (OS) in glioma patients. This study aimed to compare the long-term clinical outcomes of glioma resection under AC with those under general anesthesia (GA).

Methods: Data of 335 patients who underwent surgery with intraoperative magnetic resonance imaging for newly diagnosed gliomas of World Health Organization (WHO) grades II-IV between 2000 and 2013 were reviewed. EOR and OS were quantitatively compared between the AC and GA groups after 1:1 propensity score matching. The two groups were matched for age, preoperative Karnofsky performance status, tumor location, and pathology based on the WHO 2007 classification.

Results: After propensity score matching, 91 pairs were obtained. The median EOR were 96.1\% (interquartile range [IQR] 7.3) and 97.4\% (IQR 14.4) in the AC and GA groups, respectively ( $p=0.31)$. The median survival times were 163.3 months (95\% confidence interval [Cl] 77.9-248.7) and 143.5 months (95\% Cl 94.4-192.7) in the AC and GA groups, respectively $(p=0.585)$.

Conclusions: Even if the glioma was within or close to the eloquent area, AC was comparable with GA in terms of EOR and OS. In case of difficulties in randomizing patients with eloquent or near eloquent glioma, our propensity score-matched analysis provides retrospective evidence that $\mathrm{AC}$ can obtain EOR and OS equivalent to removing glioma under GA.

\section{Introduction}

Diffuse glioma surgery must balance neurological function preservation with maximization of tumor removal. Amassing evidence has shown that removal rates correlate with prognosis regardless of glioma World Health Organization (WHO) grade.[1-6] Studies have advocated that the extent of resection (EOR) beyond the removal target on magnetic resonance imaging (MRI) also improves prognosis.[7-10] This cytoreductive idea is derived from the infiltrative nature of gliomas. However, brain tissue removal with low tumor density is likely to decrease neurological function. Since the resection range cannot be drawn image-wise, there is no choice but to draw the resection range by awake craniotomy with intraoperative mapping (AC). Has AC improved the EOR and overall survival (OS)? The essential language and motor functions have been at the core of functional preservation efforts. [11] AC is the most suitable language/motor functional preservation method. Although there is little objection that $\mathrm{AC}$ is superior to general anesthesia (GA) for functional preservation, its ability to improve the EOR is controversial. [12-27] One reason making such validation difficult is that many studies have not evaluated the OS, despite the proven strong correlation between EOR and OS, owing to the difficulty of adjusting the bias induced by the eloquent areas. The lack of an objective definition of eloquent areas on the image is a factor, but the most critical one is the selection bias of patients who underwent surgery performed under GA despite eloquent lesions. Patients who undergo GA may have aphasia and paralysis or are elderly individuals, which also cause poor OS. Only randomized controlled trials (RCTs) can eliminate these unavoidable selection biases in patients with eloquent glioma in the GA group. However, the superiority of AC in functional preservation has been established, and RCT planning has high ethical hurdles. Therefore, we believe that propensity score-matched analysis (or pseudo-randomization) is the best method to examine the effects of AC on EOR and OS while adjusting for treatment selection bias. To our best knowledge, our propensity score-matched analysis comparing AC and GA is the first and largest study to 
quantitatively evaluate EOR and OS. This study aimed to compare the long-term clinical outcomes of glioma resection under $\mathrm{AC}$ with those under $\mathrm{GA}$.

\section{Methods}

\section{Patient Selection}

The inclusion criteria were (1) newly diagnosed glioma, including oligodendroglioma, diffuse astrocytoma, anaplastic oligodendroglioma, anaplastic astrocytoma, oligoastrocytoma, anaplastic oligoastrocytoma, and glioblastoma, based on the WHO 2007 classification; (2) surgical resection with low-field intraoperative magnetic resonance imaging (iMRI) from July 2000 to December 2013; and (3) age $\geq 18$. The exclusion criteria were biopsy and incomplete intraoperative MRI data to calculate volumetry. Our indication of AC complies with the Japanese AC guidelines.[28] A precentral gyrus tumor is an absolute indication for AC,[29] and other tumors near the pyramidal tract are relative indications. Combined use of $A C$ and motor evoked potential (MEP) monitoring improves the robustness of motor function monitoring and reduces the risk of permanent paralysis,[30] and we are actively performing AC except in cases where paralysis has already appeared before surgery. The language-dominant hemisphere is determined by referring to the dominant hand and functional MRI (fMRI).[31] Right-handedness and left lesion near the language network constitute an absolute indication. If aphasia occurs during preoperatively, AC is not performed because language mapping in AC is difficult.

\section{AC}

All patients received sleep-awake-sleep protocol anesthesia. First, craniotomy was performed under GA using a supraglottic airway device. Then, the first iMRI was performed. The patient was then awakened, and cortical mapping was used to identify language and motor areas. Tumors were removed by performing appropriate cortical/subcortical mapping with a positive mapping strategy. After evaluating the brain tumor's resection on a second MRI, the scalp was closed under mild sedation without intubation. An Ojemann cortical bipolar stimulator (OCS-1; Interga Radionics, Inc.) was used for cortical stimulation (repetitive square-wave biphasic currents of alternating polarity; intensity, 0-6 mA [biphasic currents 0-12 mA]; frequency, $50 \mathrm{~Hz}$; duration, $2 \mathrm{~s}$; interpolar distance, $5 \mathrm{~mm}$ ). The distance between the stimulation sites was 5-10 mm, and a surface electroencephalogram (bandpass filter of $10 \mathrm{~Hz}$ to $1.5 \mathrm{kHz}$ ) was recorded to detect epileptic seizures.

\section{Intraoperative MRI-guided surgery}

MR images were obtained using iMRI (0.3-T AIRIS II ${ }^{\text {TM }}$ Hitachi Medical, Chiba, Japan). The first intraoperative MR image was obtained after a dural incision to minimize the effects of brain shift. Sequential iMRI was performed before duraplasty to allow repeated resection of the residual tumor. The final iMR image was obtained after achieving the best possible resection. The tumor site, which showed positive findings in the cortex/white matter mapping during $A C$, was not removed and was preserved even if it remained on intraoperative MRI. A threedimensional volumetric measurement of the first and final iMRI studies was retrospectively conducted, as previously described.[3, 4, 32] Manual segmentation was performed with the region-of-interest analysis to measure tumor volume based on T2-weighted images in WHO grades II and III and contrast-enhanced T1-weighted MR images in grade IV. If the tumor did not show gadolinium enhancement, the T2 hyperintensity area was measured. EOR was defined as follows: (initial MR tumor volume - final MR tumor volume) / (initial MR tumor volume).

\section{Statistical analysis}


Statistical analyses were performed using SPSS Statistics, Version 25.0 (IBM Corp, Armonk, NY, USA). Categorical variables were compared using the chi-square test. The Mann-Whitney $U$ test and t-test were used for continuous nonparametric and parametric variables, respectively. OS analysis was performed using Kaplan-Meier curves and log-rank tests. P-values $<0.05$ were considered significant.

\section{Propensity score-matched analysis}

To overcome the bias arising from the lack of randomization and heterogeneity of glioma patients, one-to-one matching without replacement was performed using the nearest-neighbor match on the logit of the propensity score with caliper width set to 0.2 times the standard deviation of the logit of the propensity score. The distribution of each characteristic mentioned below in the two groups was assessed with the standardized mean difference, calculated as the difference in the means or proportions of a variable divided by the pooled estimate of its standard deviation. [33] Standard mean difference $<0.1$ between the two groups was considered an adequate balance of matching.[34] Propensity score matching was conducted using age, preoperative Karnofsky performance scale (KPS) score, pathology based on the WHO 2007 classification, and tumor location. Age, preoperative KPS, and pathological grade based on the WHO 2007 classification are commonly accepted prognostic factors for adult diffuse gliomas.[35] Most patients with eloquent gliomas underwent surgery under $\mathrm{AC}$, and patients undergoing $\mathrm{GA}$ also have a selection bias that affects prognosis because of their relatively low KPS and older age. Few studies have considered eloquent lesions as a prognostic factor. Therefore, we used the tumor's main region as an alternative variable to investigate the effect of AC on EOR and OS.

\section{Results}

\section{Patient's characteristics}

A total of 335 patients who underwent surgery with iMRI for newly diagnosed gliomas of WHO grade II-IV between 2000 and 2013 were analyzed. Patient characteristics are shown in Table 1. Before propensity score matching, patients were significantly older in the AC group than in the GA group $(\mathrm{p}<0.001)$. The male/female ratio was not significantly different $(p=0.499)$. The left hemisphere, with a high proportion of eloquent lesions, was significantly more affected in the AC group ( $p<0.001)$. The main tumor location in the AC group was the fronto-temporo-parietal cortex, including the insula near the language network and motor pathway $(p<0.001)$. Grade II-III tumors were predominant over glioblastoma $(p<0.001)$. The preoperative KPS score was higher in the AC group than in the GA group $(p<0.001)$, while the preoperative tumor volume was not significantly different between the two groups $(p=$ 0.738).

\section{Analysis after propensity score matching}

After matching, no differences were found in the mean age $(p=0.997)$, tumor location $(p=0.959)$, pathology $(p=$ $0.966)$, or mean preoperative KPS ( $p=0.722)$. Moreover, the standardized mean difference results demonstrated negligible or small differences in all characteristics between the two groups.

The adjusted covariates were well balanced in the propensity score-matched cohort with a standardized mean difference of $<0.1$ (Table 1), although the proportion of left hemisphere tumors, a factor that was not adjusted, remained higher in the $\mathrm{AC}$ group.

Table 1. Patient characteristics and group comparison before and after propensity score matching 


\begin{tabular}{|c|c|c|c|c|c|c|c|}
\hline \multirow[b]{2}{*}{ Characteristics } & \multicolumn{3}{|c|}{ Before propensity score matching } & \multicolumn{4}{|c|}{ After propensity score matching } \\
\hline & AC & GA & $p$-value & AC & GA & $p$-value & $\begin{array}{l}\text { Standardized } \\
\text { mean } \\
\text { difference }\end{array}$ \\
\hline No. of patients & 113 & 222 & & 91 & 91 & & \\
\hline $\begin{array}{l}\text { Age, years } \\
(\text { mean } \pm S D)\end{array}$ & $40.8 \pm 12.2$ & $\begin{array}{l}49.2 \\
\pm 15.7\end{array}$ & $p<0.001$ & $41.1 \pm 12.3$ & $41.4 \pm 13.5$ & 0.997 & 0.002 \\
\hline Male/female sex & $70 / 43$ & $129 / 93$ & 0.499 & $59 / 32$ & $50 / 41$ & 0.173 & 0.203 \\
\hline $\begin{array}{l}\text { Side of the tumor } \\
\text { (right/left) }\end{array}$ & $23 / 90$ & $124 / 88$ & $p<0.001$ & 19/72 & $57 / 32$ & $p<0.001$ & 0.970 \\
\hline $\begin{array}{l}\text { Main location, } \\
\text { number (\%) }\end{array}$ & & & $p<0.001$ & & & 0.959 & 0.081 \\
\hline Frontal lobe & $82(73)$ & $90(41)$ & & $62(68)$ & $59(65)$ & & \\
\hline Temporal lobe & $11(10)$ & $43(19)$ & & $10(11)$ & $12(13)$ & & \\
\hline Insula & $11(10)$ & $24(11)$ & & $10(11)$ & $11(12)$ & & \\
\hline Parietal lobe & $9(8)$ & $38(17)$ & & $9(10)$ & $9(10)$ & & \\
\hline Occipital lobe & $0(0)$ & $12(5)$ & & $0(0)$ & $0(0)$ & & \\
\hline Basal ganglia & $0(0)$ & $2(1)$ & & $0(0)$ & $0(0)$ & & \\
\hline Thalamus & $0(0)$ & $4(2)$ & & $0(0)$ & $0(0)$ & & \\
\hline Corpus callosum & $0(0)$ & $3(1)$ & & $0(0)$ & $0(0)$ & & \\
\hline Brainstem & $0(0)$ & $4(2)$ & & $0(0)$ & $0(0)$ & & \\
\hline Cerebellum & $0(0)$ & $2(1)$ & & $0(0)$ & $0(0)$ & & \\
\hline $\begin{array}{l}2007 \text { WHO grade, } \\
\text { number (\%) }\end{array}$ & & & $p<0.001$ & & & 0.987 & 0.024 \\
\hline WHO grade II & $53(47)$ & $52(23)$ & & $39(43)$ & $40(44)$ & & \\
\hline WHO grade III & $46(41)$ & $65(29)$ & & $38(42)$ & $37(41)$ & & \\
\hline WHO grade IV & $14(12)$ & $105(47)$ & & $14(15)$ & $14(15)$ & & \\
\hline $\begin{array}{l}2007 \text { WHO } \\
\text { classification, } \\
\text { number (\%) }\end{array}$ & & & $p<0.001$ & & & 0.966 & 0.176 \\
\hline Glioblastoma & $14(12)$ & $105(47)$ & & $14(15)$ & $14(15)$ & & \\
\hline $\begin{array}{c}\text { Anaplastic } \\
\text { astrocytoma }\end{array}$ & $13(12)$ & 29 (13) & & $12(13)$ & $12(13)$ & & \\
\hline $\begin{array}{l}\text { Anaplastic } \\
\text { oligodendroglioma }\end{array}$ & $19(17)$ & $14(6)$ & & $14(15)$ & $13(14)$ & & \\
\hline $\begin{array}{l}\text { Anaplastic } \\
\text { oligoastrocytoma }\end{array}$ & $14(12)$ & $22(10)$ & & $12(13)$ & $12(13)$ & & \\
\hline Diffuse & $13(12)$ & $12(5)$ & & $6(7)$ & $9(10)$ & & \\
\hline
\end{tabular}




\begin{tabular}{|c|c|c|c|c|c|c|c|}
\hline Oligodendroglioma & $23(20)$ & $25(11)$ & & $19(21)$ & $21(23)$ & & \\
\hline Oligoastrocytoma & $17(15)$ & $15(7)$ & & $14(15)$ & $10(11)$ & & \\
\hline $\begin{array}{l}\text { Median } \\
\text { preoperative KPS } \\
\text { [IQR] }\end{array}$ & 100 [10] & $90[20]$ & $p<0.001$ & 100 [10] & 100 [10] & 0.633 & 0.002 \\
\hline $\begin{array}{l}\text { Mean preoperative } \\
\text { tumor volume, } \mathrm{cm}^{3} \\
(\mathrm{mean} \pm \mathrm{SD})\end{array}$ & $45.5 \pm 37.6$ & $44.0 \pm 39.4$ & 0.738 & $44.4 \pm 39.0$ & $42.9 \pm 41.0$ & 0.722 & $<0.001$ \\
\hline
\end{tabular}

AC, awake craniotomy; GA, general anesthesia; IQR, interquartile range; KPS, Karnofsky performance status; SD, standard deviation

\section{Post-hoc analysis for prognostic factors}

Isocitrate dehydrogenase (IDH) mutation and 1p19q codeletion status were examined in the cohorts after propensity score matching. In 26 cases, the 1p19q status could not be identified. However, the percentage of 1p19q codeletion was not significantly different between the groups (Table $2 ; p=0.397$ ). The IDH status of 16 individuals was unknown, but no significant difference was found in the prevalence of IDH mutations (Table 2; $p=0.131$ ). We also examined the proportion of patients who received radiation therapy and chemotherapy in the two groups, finding no significant differences in nimustine hydrochloride or temozolomide usage $(p=0.741)$ nor in the administration of radiation therapy (Table $2 ; \mathrm{p}=0.532$ ). 
Table 2

Glioma prognostic factors in propensity-matched cases.

\begin{tabular}{|c|c|c|c|}
\hline & AC & GA & p Value \\
\hline No. of patients & 91 & 91 & \\
\hline 1p19q status, number (\%) & & & 0.397 \\
\hline Codeletion & $39(43)$ & $39(43)$ & \\
\hline Non-codeletion & $42(46)$ & $36(40)$ & \\
\hline N. D. & $10(11)$ & $16(18)$ & \\
\hline IDH status, number (\%) & & & 0.131 \\
\hline IDH-mutated & $66(73)$ & $64(70)$ & \\
\hline IDH-wildtype & $14(15)$ & $22(24)$ & \\
\hline N. D. & $11(12)$ & $5(5)$ & \\
\hline Chemotherapy, number (\%) & & & 0.741 \\
\hline ACNU-based & $44(48)$ & $39(42)$ & \\
\hline TMZ & $10(11)$ & $12(13)$ & \\
\hline None & $37(40)$ & $40(43)$ & \\
\hline Radiation therapy, number (\%) & & & 0.532 \\
\hline Yes & $62(68)$ & $58(63)$ & \\
\hline No & $29(32)$ & $33(36)$ & \\
\hline \multicolumn{4}{|c|}{$\begin{array}{l}\mathrm{AC} \text {, awake craniotomy; GA, general anesthesia; ACNU, nimustine hydrochloride; TMZ, temozolomide; IDH, } \\
\text { isocitrate dehydrogenase }\end{array}$} \\
\hline N.D., not determined & & & \\
\hline
\end{tabular}

\section{EOR, postoperative KPS, and OS}

The EOR calculated by volumetry and the KPS scores are shown in Table 3. The median removal rates were $96.1 \%$ and $97.4 \%$ in the AC group and GA group, respectively, showing no significant difference. Three months after surgery, the median KPS values in both groups decreased by 10 points compared with the preoperative values. Interestingly, KPS scores did not decrease in grade II tumors but decreased the most in the grade IV GA group (Table $3 ; p=0.137$ ). The median survival time was not significantly different between the AC (163.3 months) and GA (143.5 months) groups (Fig. 1.A). Although the median survival time could not be calculated for grade II patients, the mean survival time was 143.4 months $(95 \% \mathrm{Cl} 125.2-161.7)$ in the $\mathrm{AC}$ group and 135.8 months $(95 \% \mathrm{Cl} 121.0-150.6)$ in the GA group, without significant difference (Fig. 1.B). No significant difference was found in the median survival of grade III patients between the AC group (163.3 months, 95\% Cl 150.0-176.7) and the GA group (143.5 months, 95\% Cl 81.0206.1; Fig. 1.C). No significant difference was observed in the median survival of grade IV patients between the AC group (30.4 months, 95\% Cl 23.9-36.9) and the GA group (16.0 months, 95\% Cl 2.7-29.2; Fig. 1.D). 
Table 3

Clinical outcomes in the propensity-matched cases.

\begin{tabular}{|c|c|c|c|}
\hline & AC & GA & p Value \\
\hline \multicolumn{4}{|c|}{ EOR, \%, median [IQR] } \\
\hline Total & $96.1[17.3]$ & $97.4[14.4]$ & 0.310 \\
\hline WHO grade II & $92.8[14.1]$ & 93.4 [18.7] & 0.965 \\
\hline WHO grade III & $94.3[31.9]$ & 98.4 [13.5] & 0.108 \\
\hline WHO grade IV & $100[0.48]$ & $100[1.1]$ & 0.982 \\
\hline \multicolumn{4}{|c|}{$\mathrm{EOR}, \%$, mean $\pm \mathrm{SD}[95 \% \mathrm{Cl}]$} \\
\hline Total & $85.8 \pm 22.0[81.2-90.4]$ & $89.0 \pm 17.5[85.3-92.6]$ & 0.277 \\
\hline WHO grade II & $84.8 \pm 22.2[77.6-92.0]$ & $85.3 \pm 19.4[79.1-91.5]$ & 0.916 \\
\hline WHO grade III & $81.7 \pm 24.0[73.8-89.6]$ & $89.6 \pm 17.4[83.8-95.4]$ & 0.107 \\
\hline WHO grade IV & $99.5 \pm 1.0[95.1-100.6]]$ & $97.9 \pm 4.8[95.1-100.6]]$ & 0.231 \\
\hline \multicolumn{4}{|c|}{ Preoperative KPS, median [IQR] } \\
\hline Total & $100[10]$ & $100[10]$ & 0.633 \\
\hline WHO grade II & $100[10]$ & $100[0]$ & 0.528 \\
\hline WHO grade III & $100[10]$ & $100[10]$ & 0.827 \\
\hline WHO grade IV & $90[10]$ & $90[13]$ & 0.804 \\
\hline \multicolumn{4}{|c|}{$\begin{array}{l}\text { KPS } 3 \text { months after surgery, median } \\
{[\text { [IQR] }}\end{array}$} \\
\hline Total & $90[20]$ & $90[20]$ & 0.384 \\
\hline WHO grade II & $100[10]$ & $100[10]$ & 0.354 \\
\hline WHO grade III & $90[20]$ & $90[30]$ & 0.221 \\
\hline WHO grade IV & 90 [25] & $80[32.5]$ & 0.137 \\
\hline
\end{tabular}

\section{Discussion}

In a comparative study of GA and AC, the largest analysis was performed with the prognostic factors adjusted by propensity score. This study showed that AC for eloquent glioma was comparable with GA in terms of EOR and OS.

\section{Superiority in propensity score-matched analysis for bias adjustment}

We compared our study to previous articles comparing AC versus GA-adjusted background factors (Table 4). When considering the effect of AC on OS, it is challenging to consider a control group for AC other than GA. However, in 
retrospective or prospective designs, there will always be significant differences between the characteristics of patients undergoing AC and GA. The AC group had better KPS score and younger age before propensity score matching (Table 1). The same table also shows that lower-grade cases are biased toward AC, inevitably implying that cases with good prognosis are biased toward the AC group. The most direct way to establish effectiveness of $\mathrm{AC}$ is to randomize patients with glioma near eloquent areas. Only one RCT concluded that removal rate and functional preservation were significantly worse in the AC group.[26] As that the superiority of AC in terms of functional preservation has become commonly accepted, it is becoming challenging to implement RCTs ethically. To our knowledge, only one RCT is planned for glioblastoma.[36] The selection criteria include the condition that the neurosurgeon can remove the tumor in both surgical procedures, cleverly avoiding ethical issues. We considered propensity score-matched analysis as the most suitable for examining the effects of AC on OS in a retrospective analysis. 
Table 4

Studies comparing patients undergoing awake craniotomy (AC) vs general anesthesia (GA) after bias adjustment

\begin{tabular}{|c|c|c|c|c|c|c|c|}
\hline \multirow{2}{*}{$\begin{array}{l}\text { Study } \\
\text { Suarez-Meade } \\
\text { et al., } 2020^{12}\end{array}$} & \multirow[t]{2}{*}{ Object } & \multirow{2}{*}{$\begin{array}{l}\text { Study design } \\
\text { (bias adjustment) } \\
\text { Review meta-analysis }\end{array}$} & \multirow{2}{*}{$\begin{array}{l}\text { No. of } \\
\text { patient } \\
\text { AC, GA } \\
437 \\
1892\end{array}$} & \multicolumn{2}{|c|}{$\begin{array}{l}\text { EOR } \\
\text { AC vs GA }\end{array}$} & \multirow{2}{*}{$\begin{array}{l}\text { OS } \\
\text { n.a. }\end{array}$} & \multirow{2}{*}{$\begin{array}{l}\text { Functional } \\
\text { preservation } \\
A C=G A\end{array}$} \\
\hline & & & & $\begin{array}{l}\mathrm{AC} \\
> \\
\mathrm{GA}\end{array}$ & $\begin{array}{l}90.1 \% \text { vs } \\
81.7 \%(p= \\
0.06)\end{array}$ & & \\
\hline Bu et al., $2020^{13}$ & & Review meta-analysis & $\begin{array}{l}499 \\
334\end{array}$ & $\begin{array}{l}\mathrm{AC} \\
> \\
\mathrm{GA}\end{array}$ & $\begin{array}{l}\text { Pooled risk } \\
\text { ratio } 0.81\end{array}$ & n.a. & $A C>G A$ \\
\hline $\begin{array}{l}\text { Brown et al., } \\
2016^{22}\end{array}$ & & Review & $\begin{array}{l}411 \\
540\end{array}$ & $\begin{array}{l}\text { AC } \\
< \\
\text { GA }\end{array}$ & $\begin{array}{l}\text { Mean GTR } \\
41 \% \text { vs } 44 \%\end{array}$ & n.a. & $A C>G A$ \\
\hline $\begin{array}{l}\text { Gerritsen et al., } \\
2020^{16}\end{array}$ & GIV & $\begin{array}{l}\text { Retrospective } \\
\text { (propensity score- } \\
\text { matched) }\end{array}$ & $\begin{array}{l}37 \\
111\end{array}$ & $\begin{array}{l}\text { AC } \\
> \\
\text { GA }\end{array}$ & $\begin{array}{l}94.89 \% \text { vs } \\
70.30(p< \\
0.001)\end{array}$ & $\begin{array}{l}\mathrm{AC} \\
= \\
\mathrm{GA}\end{array}$ & $A C>G A$ \\
\hline $\begin{array}{l}\text { Eseonu et al., } \\
2017^{19}\end{array}$ & GII-IV & $\begin{array}{l}\text { Retrospective (matched } \\
\text { pairs) }\end{array}$ & 27,31 & $\begin{array}{l}\mathrm{AC} \\
= \\
\mathrm{GA}\end{array}$ & $\begin{array}{l}86.3 \% \text { vs } \\
79.6 \%(p= \\
0.136)\end{array}$ & n.a. & $A C>G A$ \\
\hline $\begin{array}{l}\text { Martino et al., } \\
2013^{21}\end{array}$ & GII & $\begin{array}{l}\text { Retrospective (matched } \\
\text { pairs) }\end{array}$ & 11,11 & $\begin{array}{l}\text { AC } \\
> \\
\text { GA }\end{array}$ & $\begin{array}{l}91.7 \% \text { vs } \\
48.7 \%(p= \\
0.001)\end{array}$ & n.a. & $A C>G A$ \\
\hline $\begin{array}{l}\text { Duffau et al., } \\
2005^{27}\end{array}$ & GII & $\begin{array}{l}\text { Retrospective } \\
\text { (chronological } \\
\text { comparison) }\end{array}$ & $\begin{array}{l}100 \\
122\end{array}$ & $\begin{array}{l}\mathrm{AC} \\
> \\
\mathrm{GA}\end{array}$ & $\begin{array}{l}\text { GTR rate } 21.6 \% \\
\text { vs } 6.0 \%\end{array}$ & $\begin{array}{l}\mathrm{AC} \\
> \\
\mathrm{GA}\end{array}$ & $A C>G A$ \\
\hline $\begin{array}{l}\text { Pichierri et al., } \\
2019^{15}\end{array}$ & GII-IV & $\begin{array}{l}\text { Retrospective (matched } \\
\text { pairs) }\end{array}$ & 20,26 & $\begin{array}{l}\mathrm{AC} \\
= \\
\mathrm{GA}\end{array}$ & $\begin{array}{l}\text { GTR rate } 60.0 \% \\
\text { vs } 53.8 \%\end{array}$ & $\begin{array}{l}\text { AC } \\
> \\
\text { GA }\end{array}$ & $A C>G A$ \\
\hline $\begin{array}{l}\text { Tuominen et al., } \\
2013^{20}\end{array}$ & GI-IV & $\begin{array}{l}\text { Retrospective (matched } \\
\text { pairs) }\end{array}$ & 20,20 & $\begin{array}{l}\mathrm{AC} \\
= \\
\mathrm{GA}\end{array}$ & $\begin{array}{l}\text { GTR rate } 50.0 \% \\
\text { vs } 55.0 \%\end{array}$ & n.a. & $A C>G A$ \\
\hline This study & GII-IV & $\begin{array}{l}\text { Retrospective } \\
\text { (propensity score- } \\
\text { matched) }\end{array}$ & 91,91 & $\begin{array}{l}\mathrm{AC} \\
= \\
\mathrm{GA}\end{array}$ & $\begin{array}{l}96.1 \% \text { vs. } \\
97.4 \%(p= \\
0.83)\end{array}$ & $\begin{array}{l}\mathrm{AC} \\
= \\
\mathrm{GA}\end{array}$ & $A C=G A$ \\
\hline
\end{tabular}

AC, awake craniotomy; G, WHO grade; GA, general anesthesia; KPS, Karnofsky performance status; OS, overall survival; RCT, randomized controlled study; IQR, interquartile range; EOR, extent of resection; n.a., not available; GTR, gross total resection

\section{EOR and OS}

There is much debate on whether AC improves the resection rate. Some reports have stated that the removal rate is improved,[12, 13, 16, 21, 23, 24, 27] while others reported a decrease or no significant difference.[14, 15, 18-20, 22, 26] The best way to address this issue is to confirm that the resection rate correlates with prognosis. Most studies are limited to the analysis of the functional outcome. Gerritsen et al. used propensity score-matched analysis limited to grade IV to show that AC improved EOR, but not OS,[16] and attributed the lack of significance to a sample size issue. Pichierri et al. showed the same resection rate for AC and GA, but better OS with AC[15]: Postoperative neural 
function might have affected prognosis. Although Sacko et al. evaluated the OS of glioma patients, data from tumors other than glioma were included in the analysis of resection rates.[23] OS data of Duffau et al. and Gravesteijn et al. were not quantitative evaluations using Kaplan-Meier curves.[18, 27] Our data are consistent with the absence of significant differences in EOR and OS between the AC and GA groups, proving the validity of the results.

\section{Difference between $\mathrm{AC}$ and $\mathrm{GA}$ resection rates}

According to Chang et al., a false eloquent area is presumed to be eloquent based on preoperative fluid-attenuated inversion recovery (FLAIR)/T2 imaging but is not eloquent based on the AC mapping.[37] A true eloquent area is presumed to be eloquent based on anatomical preoperative FLAIR/T2 imaging and is confirmed as such by AC mapping. They concluded that AC mapping improved the removal rate and prognosis when the T2/FLAIR tumor area was a false eloquent. By contrast, if it was a true eloquent, the prognosis did not change, and the EOR was the same as in the GA group. Considering the lack of significant difference in KPS scores between the AC and GA groups before and 3 months after surgery in diffuse gliomas including grades II-IV, the lack of difference in AC and GA removal rates suggested that a false eloquent contained more of the iMRI removal target than the true eloquent. In the sub-analysis of grade II gliomas, no difference was found in the removal rate, OS, or postoperative KPS between the two groups (Table 3, Fig. 1.B). Our data suggest that there was little true eloquence in the grade II T2 regions. Grade IV sub-analysis showed no difference in EOR, but KPS scores tended to be superior in the GA group than in the AC group, contrary to what was observed in other grades. The EOR result can confirm the long-standing belief that there are no functional fields in the gadolinium-enhanced lesions of glioblastoma. Although there was no significance for OS, a divergence could be observed at the beginning of the Kaplan-Meier curves. Surprisingly, in glioblastoma, AC may have reduced early mortality by preventing an early postoperative decline in KPS (Fig. 1D, Table 3). The recent meta-analysis by Gerritsen et al. of AC for high-grade glioma also suggests the efficacy of AC and is in the process of being validated by RCTs in grade IV tumors.[16, 36, 38]

\section{Effect of genetics and postoperative treatment}

This study was not based on the WHO 2016 classification, as we could not analyze the 1p19q codeletion status in the early 2000s. In principle, we could have eliminated these cases, but since OS analysis was among the main purposes of the study, these cases and those with grades II-III require long follow-up. Recently, however, IDH status and $1 p 19 q$ coding have been considered strict prognostic factors. $[39,40]$ The IDH status of 16 patients was unknown, but no significant difference was found between the AC and GA groups $(p=0.131)$. Most of the cases whose IDH status could not be identified were glioblastoma. At our facility, gene mutation search was not actively performed in the past for cases pathologically classified as glioblastoma. Approximately $90 \%$ of glioblastoma cases are IDH-wild type, in agreement with previous estimates.[40] In 26 cases, the 1p19q status could not be identified. However, since the percentage of $1 p 19 q$ codeletion was not significantly different between the groups $(p=0.397)$, the effects of prognostic genetic factors are considered small, although we could not analyze $0^{6}$-methylguanine $\left(0^{6}\right.$ MeG)-DNA methyltransferase promoter methylation status.

The inclusion of all gliomas in our analysis has an effect on post-treatment and may affect the analysis of prognosis. Our facility does not actively perform AC when we suspect glioblastoma. Indeed, glioblastoma is typically already symptomatic at the time of discovery and is often not indicated for AC, as shown in Table 1. Besides, it is not possible to accurately assess the WHO grade in the preoperative image. The reason for simultaneously analyzing tumors of different WHO grades was to reduce the selection bias. Furthermore, in the post-hoc analysis, no difference was noted after treatment between the AC group and the GA group, and the effect on prognosis was considered small. 


\section{Limitations}

Our study is inherently limited by its retrospective design, leading to selection bias, lack of randomization, limited control of confounding factors, and difficulty in establishing causes and effects. Moreover, it did not adjust for eloquent area lesions when comparing the AC and GA groups. The selection of glioma patients should be limited to near eloquent lesions to investigate the effects of AC on EOR and OS, and previous studies have attempted to do so. Paradoxically, adjusting for eloquent lesions makes it difficult to adjust for KPS and age, which affects the OS; moreover, the small number of eloquent cases in the GA group leads to small sample size studies. There were 12/91 (13\%) patients with near eloquent lesions in the GA group, although the analysis performed when excluding them did not change the results (data not shown). However, excluding the eloquent group from the GA group creates a bias for OS analysis. Besides, the cohort adjusted for eloquence is fundamentally enriched in perirolandic glioma cases, because eloquent glioma, which is an indication for GA, is abundant in the motor area and is considered less prevalent in the language-related area. Given that the most prominent feature of $A C$ is preserving language function, this method is also limited. We believe that propensity score-matched analysis is the best adjustment for assessing EOR and OS in non-RCT studies.

\section{Conclusions}

Our extensive study quantitatively evaluated AC and GA removal rates and adjusted for bias with propensity score matching. If it is difficult to plan an RCT for patients with eloquent glioma, our propensity score-matched study provided retrospective evidence that $\mathrm{AC}$ can obtain EOR and OS equivalent to removing glioma under GA.

\section{Declarations}

Funding: This research did not receive any specific grant from funding agencies in the public, commercial, or not-forprofit sectors.

Conflict of Interest: Not applicable.

Availability of data and material: The datasets generated during and/or analyzed during the current study are available from the corresponding author on reasonable request.

Authors' contributions: All authors contributed substantially to this work.

Ethics approval: This retrospective study was approved by the institutional review board of Tokyo Women's Medical University.

Consent to participate: Not applicable.

Consent for publication: Not applicable.

\section{References}

1. Patel T, Bander ED, Venn RA, Powell T, Cederquist GY, Schaefer PM, Puchi LA, Akhmerov A, Ogilvie S, Reiner AS, Moussazadeh N, Tabar V (2018) The Role of Extent of Resection in IDH1 Wild-Type or Mutant Low-Grade Gliomas. Neurosurgery 82: 808-814 doi:10.1093/neuros/nyx265 
2. Nitta M, Muragaki Y, Maruyama T, Ikuta S, Komori T, Maebayashi K, Iseki H, Tamura M, Saito T, Okamoto S, Chernov M, Hayashi M, Okada Y (2015) Proposed therapeutic strategy for adult low-grade glioma based on aggressive tumor resection. Neurosurg Focus 38: E7 doi:10.3171/2014.10.Focus14651

3. Fukui A, Muragaki Y, Saito T, Maruyama T, Nitta M, Ikuta S, Kawamata T (2017) Volumetric Analysis Using LowField Intraoperative Magnetic Resonance Imaging for 168 Newly Diagnosed Supratentorial Glioblastomas:

Effects of Extent of Resection and Residual Tumor Volume on Survival and Recurrence. World Neurosurg 98: 7380 doi:10.1016/j.wneu.2016.10.109

4. Fujii Y, Muragaki Y, Maruyama T, Nitta M, Saito T, Ikuta S, Iseki H, Hongo K, Kawamata T (2018) Threshold of the extent of resection for WHO Grade III gliomas: retrospective volumetric analysis of 122 cases using intraoperative MRI. J Neurosurg 129: 1-9 doi:10.3171/2017.3.JNS162383

5. Brown TJ, Brennan MC, Li M, Church EW, Brandmeir NJ, Rakszawski KL, Patel AS, Rizk EB, Suki D, Sawaya R, Glantz M (2016) Association of the Extent of Resection With Survival in Glioblastoma: A Systematic Review and Meta-analysis. JAMA Oncol 2: 1460-1469 doi:10.1001/jamaoncol.2016.1373

6. Albuquerque LAF, Almeida JP, de Macêdo Filho LJM, Joaquim AF, Duffau H (2020) Extent of resection in diffuse low-grade gliomas and the role of tumor molecular signature-a systematic review of the literature. Neurosurg Rev doi:10.1007/s10143-020-01362-8

7. Dimou J, Beland B, Kelly J (2020) Supramaximal resection: A systematic review of its safety, efficacy and feasibility in glioblastoma. J Clin Neurosci 72: 328-334 doi:10.1016/j.jocn.2019.12.021

8. Jackson C, Choi J, Khalafallah AM, Price C, Bettegowda C, Lim M, Gallia G, Weingart J, Brem H, Mukherjee D (2020) A systematic review and meta-analysis of supratotal versus gross total resection for glioblastoma. J Neurooncol 148: 419-431 doi:10.1007/s11060-020-03556-y

9. Li YM, Suki D, Hess K, Sawaya R (2016) The influence of maximum safe resection of glioblastoma on survival in 1229 patients: Can we do better than gross-total resection? J Neurosurg 124: 977-988 doi:10.3171/2015.5.Jns142087

10. Rossi M, Gay L, Ambrogi F, Nibali MC, Sciortino T, Puglisi G, Leonetti A, Mocellini C, Caroli M, Cordera S, Simonelli M, Pessina F, Navarria P, Pace A, Soffietti R, Rudà R, Riva M, Bello L (2020) Association of Supratotal Resection with Progression-Free Survival, Malignant Transformation, and Overall Survival in Lower-Grade Gliomas. Neuro Oncol doi:10.1093/neuonc/noaa225

11. De Witt Hamer PC, Robles SG, Zwinderman AH, Duffau H, Berger MS (2012) Impact of intraoperative stimulation brain mapping on glioma surgery outcome: a meta-analysis. J Clin Oncol 30: 2559-2565 doi:10.1200/JCO.2011.38.4818

12. Suarez-Meade P, Marenco-Hillembrand L, Prevatt C, Murguia-Fuentes R, Mohamed A, Alsaeed T, Lehrer EJ, Brigham T, Ruiz-Garcia H, Sabsevitz D, Middlebrooks EH, Bechtle PS, Quinones-Hinojosa A, Chaichana KL (2020) Awake vs. asleep motor mapping for glioma resection: a systematic review and meta-analysis. Acta Neurochir (Wien) 162: 1709-1720 doi:10.1007/s00701-020-04357-y

13. Bu LH, Zhang J, Lu JF, Wu JS (2020) Glioma surgery with awake language mapping versus generalized anesthesia: a systematic review. Neurosurg Rev doi:10.1007/s10143-020-01418-9

14. Zelitzki R, Korn A, Arial E, Ben-Harosh C, Ram Z, Grossman R (2019) Comparison of Motor Outcome in Patients Undergoing Awake vs General Anesthesia Surgery for Brain Tumors Located Within or Adjacent to the Motor Pathways. Neurosurgery 85: E470-e476 doi:10.1093/neuros/nyz007

15. Pichierri A, Bradley M, lyer V (2019) Intraoperative Magnetic Resonance Imaging-Guided Glioma Resections in Awake or Asleep Settings and Feasibility in the Context of a Public Health System. World Neurosurg X 3: 100022

Page $13 / 16$ 
doi:10.1016/j.wnsx.2019.100022

16. Gerritsen JKW, Viëtor CL, Rizopoulos D, Schouten JW, Klimek M, Dirven CMF, Vincent AJE (2019) Awake craniotomy versus craniotomy under general anesthesia without surgery adjuncts for supratentorial glioblastoma in eloquent areas: a retrospective matched case-control study. Acta Neurochir (Wien) 161: $307-315$ doi:10.1007/s00701-018-03788-y

17. Magill ST, Han SJ, Li J, Berger MS (2018) Resection of primary motor cortex tumors: feasibility and surgical outcomes. J Neurosurg 129: 961-972 doi:10.3171/2017.5.Jns163045

18. Gravesteijn BY, Keizer ME, Vincent AJPE, Schouten JW, Stolker RJ, Klimek M (2018) Awake craniotomy versus craniotomy under general anesthesia for the surgical treatment of insular glioma: choices and outcomes. Neurological Research 40: 87-96 doi:10.1080/01616412.2017.1402147

19. Eseonu Cl, Rincon-Torroella J, ReFaey K, Lee YM, Nangiana J, Vivas-Buitrago T, Quiñones-Hinojosa A (2017) Awake Craniotomy vs Craniotomy Under General Anesthesia for Perirolandic Gliomas: Evaluating Perioperative Complications and Extent of Resection. Neurosurgery 81: 481-489 doi:10.1093/neuros/nyx023

20. Tuominen J, Yrjana S, Ukkonen A, Koivukangas J (2013) Awake craniotomy may further improve neurological outcome of intraoperative MRI-guided brain tumor surgery. Acta Neurochir (Wien) 155: 1805-1812 doi:10.1007/s00701-013-1837-3

21. Martino J, Gomez E, Bilbao JL, Dueñas JC, Vázquez-Barquero A (2013) Cost-utility of maximal safe resection of WHO grade II gliomas within eloquent areas. Acta Neurochirurgica 155: 41-50 doi:10.1007/s00701-012-1541-8

22. Brown T, Shah AH, Bregy A, Shah NH, Thambuswamy M, Barbarite E, Fuhrman T, Komotar RJ (2013) Awake craniotomy for brain tumor resection: the rule rather than the exception? J Neurosurg Anesthesiol 25: 240-247 doi:10.1097/ANA.0b013e318290c230

23. Sacko O, Lauwers-Cances V, Brauge D, Sesay M, Brenner A, Roux FE (2011) Awake craniotomy vs surgery under general anesthesia for resection of supratentorial lesions. Neurosurgery 68: 1192-1198; discussion 1198-1199 doi:10.1227/NEU.0b013e31820c02a3

24. De Benedictis A, Moritz-Gasser S, Duffau H (2010) Awake mapping optimizes the extent of resection for lowgrade gliomas in eloquent areas. Neurosurgery 66: 1074-1084; discussion 1084

doi:10.1227/01.Neu.0000369514.74284.78

25. Pinsker MO, Nabavi A, Mehdorn HM (2007) Neuronavigation and Resection of Lesions Located in Eloquent Brain Areas under Local Anesthesia and Neuropsychological-Neurophysiological Monitoring. Minim Invasive Neurosurg 50: 281-284 doi:10.1055/s-2007-985825

26. Gupta DK, Chandra PS, Ojha BK, Sharma BS, Mahapatra AK, Mehta VS (2007) Awake craniotomy versus surgery under general anesthesia for resection of intrinsic lesions of eloquent cortex-a prospective randomised study. Clin Neurol Neurosurg 109: 335-343 doi:10.1016/j.clineuro.2007.01.008

27. Duffau H, Lopes M, Arthuis F, Bitar A, Sichez JP, Van Effenterre R, Capelle L (2005) Contribution of intraoperative electrical stimulations in surgery of low grade gliomas: a comparative study between two series without (198596) and with (1996-2003) functional mapping in the same institution. J Neurol Neurosurg Psychiatry 76: 845851 doi:10.1136/jnnp.2004.048520

28. Kayama T (2012) The guidelines for awake craniotomy guidelines committee of the Japan awake surgery conference. Neurol Med Chir (Tokyo) 52: 119-141 doi:10.2176/nmc.52.119

29. Saito T, Muragaki Y, Tamura M, Maruyama T, Nitta M, Tsuzuki S, Fukui A, Kawamata T (2020) Correlation between localization of supratentorial glioma to the precentral gyrus and difficulty in identification of the motor area during awake craniotomy. J Neurosurg: 1-10 doi:10.3171/2020.2.Jns193471

Page $14 / 16$ 
30. Saito T, Muragaki Y, Tamura M, Maruyama T, Nitta M, Tsuzuki S, Fukuchi S, Ohashi M, Kawamata T (2019) Awake craniotomy with transcortical motor evoked potential monitoring for resection of gliomas in the precentral gyrus: utility for predicting motor function. J Neurosurg: 1-11 doi:10.3171/2018.11.Jns182609

31. Ishikawa T, Muragaki Y, Maruyama T, Abe K, Kawamata T (2017) Roles of the Wada Test and Functional Magnetic Resonance Imaging in Identifying the Language-dominant Hemisphere among Patients with Gliomas Located near Speech Areas. Neurol Med Chir (Tokyo) 57: 28-34 doi:10.2176/nmc.oa.2016-0042

32. Konishi Y, Muragaki Y, Iseki H, Mitsuhashi N, Okada Y (2012) Patterns of intracranial glioblastoma recurrence after aggressive surgical resection and adjuvant management: retrospective analysis of 43 cases. Neurol Med Chir (Tokyo) 52: 577-586 doi:10.2176/nmc.52.577

33. D. Yang JD (2012) A unified approach to measuring the effect size between two groups using SAS. Mathmatics

34. Austin PC (2011) An Introduction to Propensity Score Methods for Reducing the Effects of Confounding in Observational Studies. Multivariate Behavioral Research 46: 399-424 doi:10.1080/00273171.2011.568786

35. Weller M, van den Bent M, Preusser M, Le Rhun E, Tonn JC, Minniti G, Bendszus M, Balana C, Chinot O, Dirven L, French P, Hegi ME, Jakola AS, Platten M, Roth P, Rudà R, Short S, Smits M, Taphoorn MJB, von Deimling A, Westphal M, Soffietti R, Reifenberger G, Wick W (2020) EANO guidelines on the diagnosis and treatment of diffuse gliomas of adulthood. Nat Rev Clin Oncol doi:10.1038/s41571-020-00447-z

36. Gerritsen JKW, Klimek M, Dirven CMF, Hoop EO, Wagemakers M, Rutten GJM, Kloet A, Hallaert GG, Vincent A (2020) The SAFE-trial: Safe surgery for glioblastoma multiforme: Awake craniotomy versus surgery under general anesthesia. Study protocol for a multicenter prospective randomized controlled trial. Contemp Clin Trials 88: 105876 doi:10.1016/j.cct.2019.105876

37. Chang EF, Clark A, Smith JS, Polley MY, Chang SM, Barbaro NM, Parsa AT, McDermott MW, Berger MS (2011) Functional mapping-guided resection of low-grade gliomas in eloquent areas of the brain: improvement of longterm survival. Clinical article. J Neurosurg 114: 566-573 doi:10.3171/2010.6.Jns091246

38. Gerritsen JKW, Arends L, Klimek M, Dirven CMF, Vincent AJE (2019) Impact of intraoperative stimulation mapping on high-grade glioma surgery outcome: a meta-analysis. Acta Neurochir (Wien) 161: 99-107 doi:10.1007/s00701-018-3732-4

39. Eckel-Passow JE, Lachance DH, Molinaro AM, Walsh KM, Decker PA, Sicotte H, Pekmezci M, Rice T, Kosel ML, Smirnov IV, Sarkar G, Caron AA, Kollmeyer TM, Praska CE, Chada AR, Halder C, Hansen HM, McCoy LS, Bracci PM, Marshall R, Zheng S, Reis GF, Pico AR, O'Neill BP, Buckner JC, Giannini C, Huse JT, Perry A, Tihan T, Berger MS, Chang SM, Prados MD, Wiemels J, Wiencke JK, Wrensch MR, Jenkins RB (2015) Glioma Groups Based on 1p/19q, IDH, and TERT Promoter Mutations in Tumors. N Engl J Med 372: 2499-2508 doi:10.1056/NEJMoa1407279

40. Yan H, Parsons DW, Jin G, McLendon R, Rasheed BA, Yuan W, Kos I, Batinic-Haberle I, Jones S, Riggins GJ, Friedman H, Friedman A, Reardon D, Herndon J, Kinzler KW, Velculescu VE, Vogelstein B, Bigner DD (2009) IDH1 and IDH2 mutations in gliomas. N Engl J Med 360: 765-773 doi:10.1056/NEJMoa0808710

\section{Figures}




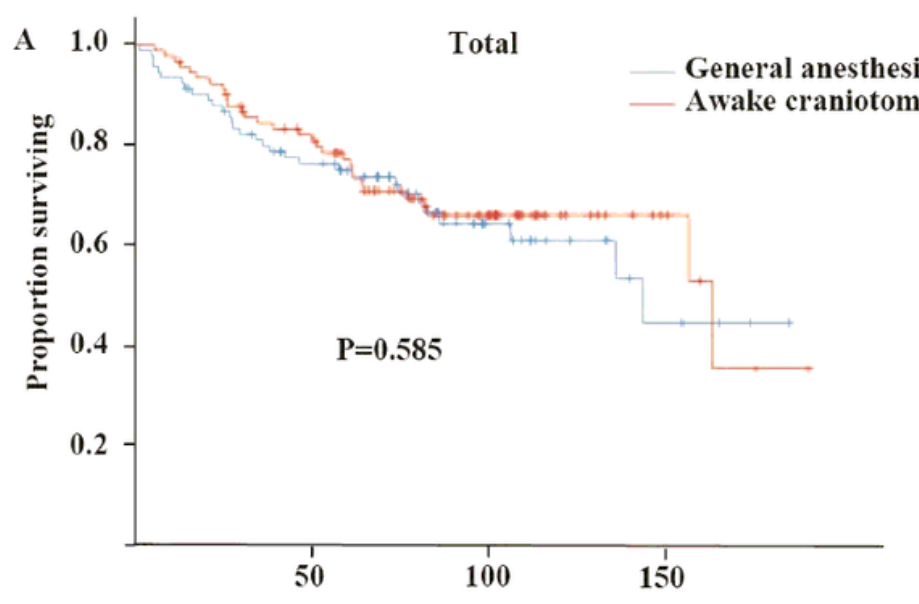

Overall survival time (month)

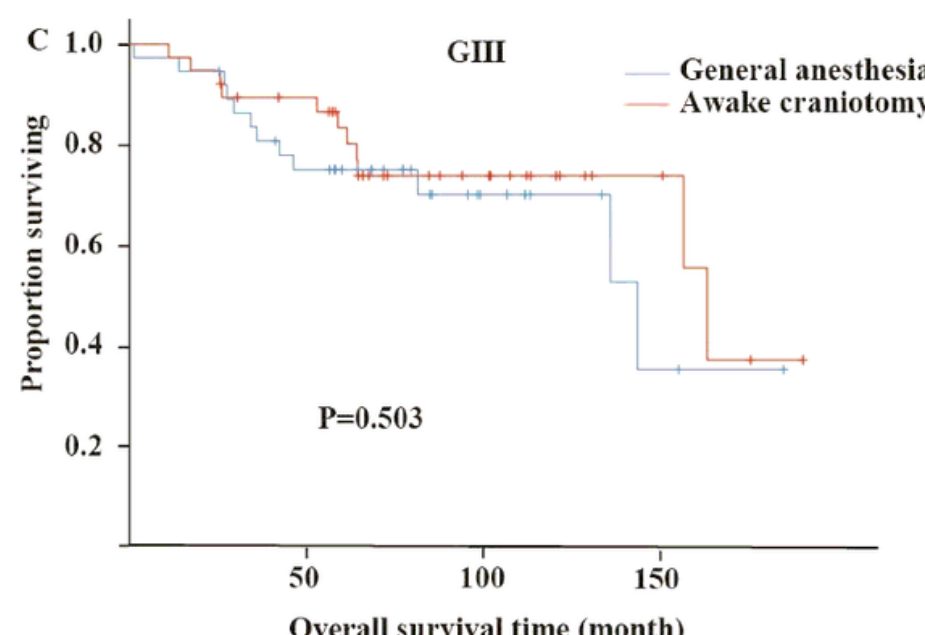

Overall survival time (month)
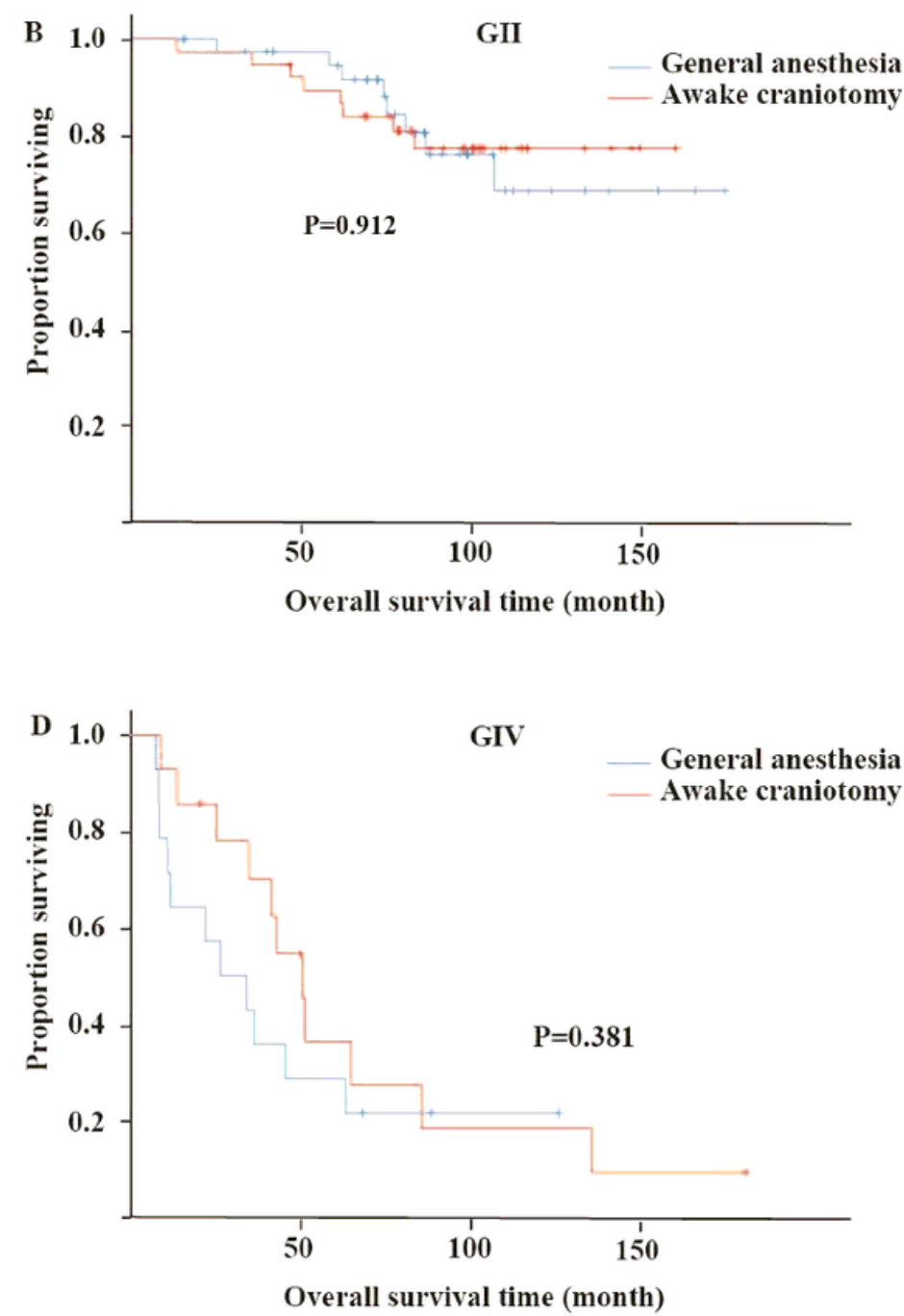

Figure 1

Kaplan-Meier estimates of overall survival compared between awake craniotomy and general anesthesia. Overall survival for all patients (A), WHO grade II (B), WHO grade III (C), and WHO grade IV (D). G, WHO grade 